Proceedings of the New Zealand Grassland Association 54: 81-84 (1992)

\title{
Resource Management Act 1991: Its impact upon the rural scene
}

\author{
Ernest New \& Associates Ltd. PO Box 1328, Invercargill
}

\begin{abstract}
The purpose of the Resource Management Act (RMA) is to promote the sustainable management of natural and physical resources and is primarily concemed with the effects of activities. Regional Councils may impose their will upon the management of natural and physical resources. Farmers adjacent to coastlines, rivers and streams may see many impacts as public access is enhanced. Landscape values must be protected and these can impinge upon nural working, productive environments. The degree to which the rural sector is affected will be determined by its input and the strictures in Regional policy statements and District plans.
\end{abstract}

Keywords sustainable management, activities, effects, public participation

\section{Introduction}

New Zealand has been subject to some form of environmental controls since the 1920s. The early 1940s saw the introduction of water and soil control, and the early 1950s saw the fist significant move towards land use planning, with the introduction of the Town and Country Planning Act. That Act had limited impact upon the nural scene, except in proximity to urban areas. The emphasis was on the direction of the use of land. This Act also endeavoured to deal with social and economic as well as land use planning, although its success was predominantly in the latter.

October 1991 brought a dramatic change to environmental control with the enactment of the Resource Management Act: RMA. The RMA followed extensive review of all legislation that dealt with land, water, air, noise, pollution, hazardous materials and the coast. In world terms, thereview process itself and the RMA were unprecedented.

The RMA must, however, be seen within the total legislative context. The Lange Labour Government set about to reform local government totally. The RMA was only one of the dynamic results.

The RMA has the potential to directly affect the rural scene in general, and agriculture in particular. Whether it will or not, and whether the affect is adverse or not, may depend upon four factors, which in turn will affect each other.

1. National policy statements, national environmental standards, the introduction and use of economic instruments at a national level: all three non-mandatory; and coastal policy statements: mandatory.

2. Regional policy statements: mandatory; regional plans: non-mandatory; regional coastal plans: mandatory.

3. District plans: mandatory.

4. The level of proactive participation at national, regional and district levels by the public.

\section{Local government change}

Although New Zealand had a few regional councils, and any number of united councils (the latter being mostly ineffective) before local government reform, their function and management bore little relationship to the purpose of the present Local Government Act. The new regional councils, with their role more focused by new legislation this year. may now start to affect the rural scene.

Many regional councils have been influenced, some may say kept under control, by councillors who served upon both regional and district or city councils. This can no longer happen after the elections this year. Regional councils, hereafter, may actually start imposing their will upon the management of natural and physical resources. For example, farmers adjacent to coastlines. rivers and streams may see many effects.

District and city councils should not be confused with the counties, boroughs and cities of the past, although some councillors are still showing signs of confusion, particularly if they served under the previous style of local government. All local government is now more open: 'transparent' is the buzz word. Councils are managed by managers: well, that was the theory behind the legislation. The incumbent Minister of Local Government seems to indicate a wish to return to the days when he was a Mayor of a small borough.

A subtle, but nevertheless significant difference with all councils. regional and district, is the elected composition a a mixture of urban and rural People in 
most cases. No longer do we have the rural scene managed by county councils, composed mostly of farmers, and urban areas managed by boroughs or city councils. This aspect has potential to affect the rural areas far more than the urban, as often the urban voice on the district or city council is more strident. Farming areas now part of a city could find themselves almost without a voice.

Thechangeinvotingrightsisyet to be felt. Nominee voters for commercial and industrial landowners, and absentee landowners now able to vote again, may well have an effect.

\section{Resource management changes}

The RMA is not just the replacement of 75 earlier laws by amalgamation, any more than the new councils are just the result of amalgamation. The whole process, in both cases, is driven by new philosophies. The RMA and the councils are quite different from their respective predecessors. Furthermore, both will act upon, andreaet to. each other. All involved will have a lot to learn quickly, which can lead, particularly in the early stages, to uncertainty.

The RMA only has one purpose, and that is to promote the sustainable management of natural and physical resources. It is a new process for the management of land, soil, water, air quality, gee-thermal energy, pollution control, noise control and the coast-

Sustainable management is defined as managing the use, development andprotection of natural andphysical resources in a way, or at a rate, which enables people and communities to provide for their social. economic, and cultural wellbeing, and for their health and safety, while:

(a) Sustaining the potential of natural and physical resources (excluding minerals) to meet the reasonably foreseeable needs of future generations; and

(b) Safeguarding the life-supporting capacity of air, water, soil, and eco-systems; and

(c) Avoiding, remedying, or mitigating any adverse effects of activities on the environment.

This is a big shift from the days of the Town and Country Planning Act. Gone are the social and economic planning goals: you should look for those through the Local Government Act and Annual Plans. Gone is the emphasis on the direction of use. The RMA is primarily concerned with the effects of activities. It accepts that you are the best judge of where to locate your intended activity, but you are personally responsible for the activity's effect upon the environment. The definition of environment is broad, it includes: (a) Ecosystems and their constituent parts, including people and communities; and

(b) AN natural and physical resources; and

(c) Amenity values; and

(d) The social, economic, aesthetic, andcultural conditions which affect the matters in (a) to (c) above, or which are affected by those matters.

The definition of effect is important. It is:

(a) Anypositive or adverse effect; and

(b) Any temporary or permanent effect; and

(c) Any past, present, or future effect; and

(d) Any cumulative effect which arises over time, or in combination with other effects - regardlessof scale, intensity, orfrequency of effect, and also includes -

(e) Any potential effect of high probability; and

(f) Any potential effect of low probability which has a high potential impact.

Equity has been introduced, both for future generations and for tangata whenua. Social planning is shifted to the Local Government Act. Social effects are now taken into account along with the environmental effects. The Crown is bound by the RMA.

\section{Environmental problems in New Zealand}

Some significant environmental problems are:

1. soil loss

2. Wetland loss

3. Disruption of water regimes

4. Pollution

5. Waste

6. Species lost

7. Unsustainable agriculture

8. Dependence on non-renewable resources

9. Urban settlement

These problems are not listed in any priority, but they are all part of, or affect, the rural scene. The RMA offers a way of mitigating, or avoiding totally, these effects. Thequestion is. willcouncils have thewillor the resources to use the RMA effectively? It must be recognised that whilst sustainability can only be achieved within ecological constraints, councils can only achieve within economic and political constraints. This is a completely new ball-game for government, councils and the rural and urban communities.

\section{Warnings for rural communities}

It is the cumulative effect-not just what youdo, but what everyone does added together. How do we make the 
decision. when is enough too much?

Landscape values must be protected and these can impinge upon rural working, productive environments.

Access to the coast, lakes, rivers and streams for the public is to be enhanced.

The relationship of Maori and their culture and traditions with their ancestral lands, water, sites, waahi tapu, and other taonga must be recognised.

Indigenous vegetation and habitat must be protected.

The natural character of the coastal environment, wetlands, lakes and rivers must be preserved and protected. There are restrictions on the use of coastal marine areas, the beds of lakes and rivers. There are restrictions on water and the discharge of contaminants.

Regard must be given to the intrinsic values of ecosystems.

Certain existing uses in relation to land are protected provided the use was lawfully established, but its effects must not change in intensity or scale.

Subdivision of land will no longer be a matter for the Local Government Act. It is now within the provisions of the RMA.

There is a duty to avoid unreasonable noise.

The level of monitoring is likely to increase markedly.

National environmental standards may be issued, prescribing the technical standards relating to the use, development and protection of natural and physical resources, noise, contaminants, water quality, level or flow, air quality. and soil quality in relation to the discharge of contaminants.

Economic instruments may be introduced by government, regional or district councils, or all three.

Any person can make a submission to a resource consent application. Resource consent conditions can be reviewed.

Particularcare will be needed when purchasing land. Liability for pollution can pass with ownership. One law firm has suggested that liability could even extend to lenders!

Offences against the RMA attract a range of penalties from up to two years' imprisonment to fines of up to $\$ 200.000$, plus $\$ 10,000$ a day for a continuing offence.

If an offence committed by an employee could have been reasonably known to a director or owner, then that director or owner is liable.

A declaration by the Planning Tribunal may, subject to certain limitations, be applied for by anyperson at any time in respect of:

* The existence or extent of any function, power, right or duty under the RMA.
* Inconsistency between provisions or proposed provision of a statement or plan.

* Acts or omissions that contravene or are likely to contravene the RMA or a rule in the plan. a designation, heritage order or a resource consent.

* Whether an act or omission is permitted, controlled, discretionary, non-complying, or prohibited, or is a breach of certain defined sections of the RMA.

An enforcement or\&r by the Planning Tribunal may, subject to certain limitations, be applied for by any person at any time in respect of:

* Requiring a person to cease, or not to commence anything that, in the opinion of the Tribunal contravenes, or is likely to contravene the RMA, any regulation, a rule in a plan, a designation, heritage order or resource consent, or is likely to be noxious, dangerous, offensive. or objectionable to such an extent that it has or may have an adverse effect on the environment.

* To ensure compliance or to avoid. remedy or mitigate any actual or likely adverse effect on the environment.

* To require a person to pay money to or reimburse any other person for any actual or reasonable costs and expenses incurred in remedying or mitigating any adverse effect caused by the person against whom the order is sought, where that person fails to comply with an abatement notice, a rule in a plan, a resource consent, or any other obligation under the RMA.

Similar provisions apply to a proposed plan. The significance of the declaration and the enforcement order provisions of the RMA is the enfranchisement of any person, not just regulatory authorities. Already these provisions are being used by commercial and industrial competitors against each other to advantage.

The rural communities need to be aware of these provisions and be conscious of the perception of many urban dwellers that the countryside is their recreation asset, and theirs as of right.

The RMA identifies the parameters within which agriculture and the processing of agricultural commodities can operate. It now remains for the rural sector to respond. A recent example of interaction has been the New Zealand Pork Industry Board setting up an Environmental Task Force. It has produced an Industry Code of Practice - it is also helping local government write rules forregional and district plans. Standards have also been adopted by the chemical industry, vegetable growers and tourism. 


\section{Sustainable agriculture}

Sustainable Agriculture was published by MAF in 1991 as a policy proposal. Submissions to the proposal indicated a diverse range of opinion regarding the sustainability of the present farming system. The sustainability of agriculture is, if not the most significant, at the very least a significant component of New Zealand's natural and physical resources. It was unfortunate that MAF failed to link with sustainability, in RMA terms, or to consider Maori needs. The Treaty of Waitangi was ignored. The question has to be asked: are the inputs from outside the system sustainable, for example, fertiliser. fuels, pesticides and insecticides?

Most land users' stewardship ethic is strong, and thus the need for the agricultural sector to participate on a partnership basis with councils in the preparation of statements and plans. The economic survival of most districts in New Zealand will depend upon the sustainable management of its land resource.

\section{The rural community's response}

The only response from the rural community must be a proactive one. The rural community must take a positive role in resource management. Each district needs to determine its own environmental bottom line. There is a need to work alongside local government and the other stakeholders at national, regional and district levels. This way it will be possible for the effects of the RMA to be positive for the rural community.

Many of the larger industries are now conducting thorough environmental audits of their operations. They are developing corporate environmental policies. Industries are reassessing all of their inputs and outputs and rethinking their whole corporate response, shifting the emphasis to sustainable management. The rural sector would be well advised to do likewise, not just to ensure it can cope with the RMA. but to ensure continued market acceptability of its products worldwide.

There is plenty of room for non-statutory documents. as a result of mediation or facilitation, resulting in stakeholder accords. It is the rural sector's choice plan with the RMA, or be planned for.

In the resource management field, it certainly is not business as usual. 